\title{
Configurações da organização tecnológica do trabalho jornalístico em rede no modelo pós-industrial: idiossincrasias e similaridades em realidades extremas
}

\section{CONFIGURATIONS OF THE TECHNOLOGICAL ORGANIZATION OF THE JOURNALISTIC WORK IN NETWORK IN THE POST-INDUSTRIAL MODEL: IDIOSYNCRASIES AND SIMILARITIES IN EXTREME REALITIES}

L Paula Melani Rocha ${ }^{1}$

ORCID: http://orcid.org/0000-0001-5525-6650

(Universidade Estadual de Ponta Grossa, Programa de Pós-Graduação em Jornalismo. Ponta Grossa - PR, Brasil).

\section{Simone Pallone de Figueiredo ${ }^{2}$}

ORCID: http:// orcid.org/0000-0001-7982-3779

(Universidade Estadual de Campinas, Laboratório de Estudos Avançados em Jornalismo. Campinas - SP, Brasil).

Recebido em 03/08/2019. Aprovado em: 07/11/2019.

\section{Resumo}

$\mathrm{O}$ artigo discute o processo de trabalho jornalístico considerando a inovação tecnológica, agentes envolvidos e modelos de gestão no jornalismo em rede do século XXI, em duas realidades distintas: empresas "tradicionais" de comunicação que migraram para o jornalismo na Internet e novas iniciativas digitais. A investigação analisa a redação online do jornal O Estado de S. Paulo e o site InfoAmazônia. Os procedimentos metodológicos envolveram entrevistas semiestruturadas, observação e análise dos sites. A discussão fundamentou-se nos estudos sobre transformações do jornalismo no modelo pós-industrial e inovação tecnológica na organização do trabalho.

Palavras-chave: Jornalismo na Internet. Inovação tecnológica. Organização do trabalho.

\section{Abstract}

The paper discusses the work process considering the technological innovation, agents involved and management models in 21st-century network journalism, in two distinct realities: "traditional" communication companies that migrated to journalism on the Internet and new digital initiatives. The investigation analyzes the online newsroom of the daily O Estado de S.Paulo and the InfoAmazônia website. The methodologies use semi-structured interviews, observation, and analysis of the sites. The discussion is based on studies on the transformations of journalism in the post-industrial model and technological innovation in the organization of work.

Keywords: Journalism on the Internet. Tecnologic innovation. Organization of work. 


\section{Introdução}

$\mathrm{O}$ artigo discute o conhecimento no jornalismo e sua prática em um cenário em transformação do campo datado a partir do final do século XX, com impacto maior no início do século XXI. O estudo tem como recorte a organização e o processo de trabalho na produção de conteúdo jornalístico, perpassando pela cultura profissional e mercado editorial. Transformações essas ocasionadas por fatores internos e externos ao mundo do jornalismo, como inovação tecnológica, Internet, crises econômica e política, globalização e instabilidade nas relações de trabalho no capitalismo pós-industrial. Para melhor apreensão desse fenômeno, definiu-se a pesquisa empírica em duas realidades concretas: o jornal O Estado de S.Paulo e o site InfoAmazônia.

A escolha dos dois veículos foi proposital por abarcar organizações distintas em relação à cronologia da conformação do jornalismo, longevidade, modelo de gestão, linha editorial, formação, morfologia das redações, bem como público/audiência. Além disso, estão distantes geograficamente. O primeiro está no eixo central do jornalismo brasileiro, em São Paulo, na região Sudeste a qual concentra em torno de $30 \%$ do mercado profissional. E o segundo é especializado na cobertura da Amazônia, na região Norte do país.

O jornal Estado de S. Paulo, um dos jornais mais tradicionais do país, foi criado em 1875, na cidade de São Paulo, com o nome de Província de São Paulo ${ }^{12}$. Com mais de um século de existência, o grupo Estado consagrou-se como empresa de comunicação no modo de produção capitalista, tornando-se um dos conglomerados nacionais. Além da publicação de jornais (Folha da Tarde e Estado de S. Paulo), o grupo dirigiu rádios (Eldorado AM e FM, Rádio Estadão), a Agência Estado e controla a OESP Gráfica S.A., que foi responsável pela impressão das listas telefônicas da capital, a partir de 20 de dezembro de 1985. A OESP Gráfica era uma das sete empresas que controlava a impressão das listas telefônicas. A importância em mencioná-la nesta reflexão é justamente por ela ter sido um dos pilares de sustentação do grupo no modelo de gestão do século XX. O controle da impressão das listas auxiliou na receita da empresa e na implementação do parque gráfico do grupo ${ }^{3}$. Contudo, essa reserva de mercado de edição dos catálogos e a

1 Em janeiro de 1890 passa a circular com o nome Estado de S. Paulo.

2 Site oficial do grupo Estado. Disponível em http://www.estadao.com.br/historico/resumo/conti1.htm Acesso em 11 de março de 2018.

${ }^{3}$ Em 1976 o grupo se instala na nova sede localizada na Av. Caetano Álvares Jr, na marginal Tietê, no bairro do Limão. O conjunto de edifícios passou a abrigar 3.195 funcionários e viabilizou a ampliação na capacidade de produção dez vezes maior que a realizada na antiga sede. De 18 rotativas saltou para 108 (JORNAL ESTADO DE S.PAULO, 30 de setembro de 2015). Disponível em: http://sao-paulo.estadao.com.br/noticias/geral,predio-do-estadao-e-referencia-nazona-norte, 1772186 Acesso em: 11 mar. 2018. 
exclusividade das negociações a cargo das companhias telefônicas gerou um monopólio contestável, culminando em um projeto de Lei Orgânica das Telecomunicações apresentado em 1996. O projeto defendia que qualquer meio poderia divulgar as listas, fosse via Internet, CD-ROM, telefone ou impresso. A prestação de serviço pela Internet tornou o serviço de impressão obsoleto, impulsionando danos aos parques gráficos que controlavam a impressão. Para se ter uma ideia do montante, a indústria de edição de listas telefônicas movimentava 350 milhões de reais por ano (LOBATO, 1996), distribuídos entre as empresas de telefonia e as sete gráficas.

O Estado de S. Paulo, em 1993, criou o projeto Estadão Multimídia, em parceria com a Agência Estado, contemplando a disseminação de informação em seis plataformas: pagers, displays, fax, BBS, voice mail e videotexto. Em maio de 2000, lançou o portal Estadao.com.br, uma fusão dos sites Agência Estado, O Estado de S. Paulo e Jornal da Tarde.

O outro veículo que compõe a análise é o site InfoAmazônia, nativo do ambiente digital da web notícia. Ele foi criado em 2012, já no contexto do século XXI e do modo de produção capitalista pós-industrial ${ }^{4}$. Compõem a nova geração de sites investigativos emergentes no cenário de disrupção da mídia, construindo audiências e gerando receitas, de acordo com o estudo do SembraMedia (2017). "O advento das mídias sociais e de ferramentas de web design fáceis de usar tornaram possível lançar um empreendimento de mídia digital quase que inteiramente com patrimônio e esforço próprio" (SEMBRAMEDIA, 2017, p.7).

Composto por uma rede de jornalistas de nove países que fazem fronteira com a Amazônia, o InfoAmazônia se propõe a fazer jornalismo independente, com cobertura segmentada sobre a Amazônia e sua diversidade ambiental, cultural e humana.

Canavilhas (2001), compreende web notícia como a configuração de um conteúdo totalmente novo que explora as potencialidades da Internet e caracteriza-se como uma mera transposição do conteúdo impresso para o online. Mais recentemente, Barbosa (2013) introduziu na dinâmica do desenvolvimento das mídias digitais a noção de continuum multimídia, definindo uma nova etapa evolutiva do jornalismo nas redes sociais, a qual classificou como quinta geração. A autora parte da categoria da medialidade (GRUSIN, 2010), que integra à produção jornalística diversos formatos de conteúdo como textos, ${ }^{4}$ A denominação capitalismo pós-industrial refere-se ao novo estágio do capitalismo decorrente de grandes mudanças nas sociedades industriais mais avançadas. "Diversos escritores se esforçam para encontrar um nome apropriado a essa sociedade emergente, mas parece-me que, até que historiadores futuros, a partir de sua perspectiva mais vantajosa e retrospectiva, inventem e concordem com seu próprio epíteto, o termo "pós-industrial" de Bell é o mais útil, porque evita neologismos e, ao mesmo tempo, conota a saída da sociedade que conhecemos (Bell, 1967)" (FREIDSON, 1998, p.134-135) 
fotos, áudios, imagens, animação, infográficos interativos, newsgames e linhas de tempo. Esses formatos auxiliam na construção do conteúdo informativo e são realizados por profissionais que empregam tecnologias digitais e em rede (BARBOSA, 2013). Assim, a construção possibilita uma continuidade narrativa entre diferentes plataformas. Nesse sentido, o InfoAmazônia se enquadra nas definições de web notícia de Canvilhas (2001) e na quinta geração conceituada por Barbosa (2013), pois trabalha com mapas interativos, bases de dados abertas, vídeos, imagens, infográficos e links para migrar para outras páginas transversais à temática da cobertura jornalística.

A sustentação financeira está ancorada em instrumentalizações realizadas pelos próprios sites que se autodenominam como jornalismo independente. Contudo o entendimento do que é jornalismo independente oscila de acordo com a visão de quem conceitua. Ribas (2017) mostra, a partir de uma revisão teórica, que o conceito de jornalismo independente apresenta caracterizações de linha editorial, público e suporte econômico. O pesquisador acrescenta que há alternâncias conceituais de acordo com o autor, porém eles compartilham a ideia de desvinculação dos interesses de grupos hegemônicos de comunicação e de uma lógica comercial.

Para catalogar as 86 iniciativas do projeto Mapa do jornalismo independente, a Agência Pública (2016) relacionou a noção de independência a projetos em plataformas digitais, de iniciação coletiva e sem vínculo com os tradicionais proprietários de veículos de comunicação. Ribas (2017) acrescenta a busca de uma autonomia "na avaliação da noticiabilidade do conteúdo jornalístico, perpassando pela escolha das fontes, valor notícia e critérios de noticiabilidade, que se distanciam das lógicas adotadas dos meios tradicionais" (RIBAS,2017, p.103). O autor sugere ainda que o aumento de sites de jornalismo independente no Brasil, sobretudo após 2010, pode estar associado às "mudanças no mercado profissional tradicional jornalístico", caracterizadas pelo enxugamento das redações, de cargos e de funções (RIBAS, 2017, p.82). O site InfoAmazônia está no Mapa da Pública e não compartilha das lógicas comerciais de sustentação financeira como será detalhado mais a frente.

O objetivo da reflexão é aferir as transformações tecnológicas na organização do processo de trabalho envolvendo o jornalismo e os instrumentos que operam no jornalismo em rede. A pergunta norteadora é: Quais características do conhecimento relacionado às práticas sociais do jornalismo em transformação podem ser reconhecidas na realidade da situação tecnológica contemporânea? Na tentativa de respondê-las e possibilitar ao leitor o entendimento do caminho percorrido na pesquisa, o artigo traz um panorama sobre as 
transformações do jornalismo no cenário nacional, o percurso teórico metodológico para a construção da análise e os resultados alcançados distribuídos em dois tópicos, um para cada veículo, pois são realidades com especificidades e o estudo não se caracterizou como análise comparativa.

\section{As transformações do jornalismo e a configuração de um novo paradigma}

As mudanças no mercado de trabalho não são exclusivas ao mundo do jornalismo tampouco restritas ao Brasil. Elas afetam os empregos, a organização das empresas e a implantação de políticas de gestão. O terceiro estágio do capitalismo resulta de uma crise do próprio modelo de produção que para manter seus pilares de sustentação (mais valia e acúmulo de capital), explora ainda mais um dos seus custos de produção, a mão de obra (ANTUNES, 2018).

Em 1994, segundo dados da Organização Internacional do Trabalho, mais de 800 milhões de pessoas estavam desempregadas ou subempregadas no mundo e a tendência era desse número aumentar no início do século XXI, impulsionado pela revolução tecnológica e pela inserção das máquinas em praticamente todos os setores e indústrias da economia global (RIFKIN,1995). Para o autor, a crise no trabalho é um dos desdobramentos da terceira grande revolução industrial, gerando problemas complexos no que ele caracterizou como era pós-mercado (RIFKIN,1995).

$\mathrm{Na}$ mesma conjuntura e pela perspectiva do trabalho, Hirata (2002, p.344) aponta que no final da segunda metade do século XX uma crise financeira abalou diferentes países ocasionando uma "tipologia complexa em fase de elaboração", a qual a autora concebeu como "transformação paradoxal do trabalho". Isso significou o envolvimento de poucas pessoas no trabalho e a precarização de muitos. Ainda no cerne da problematização, esse aumento da precarização do emprego e do desemprego sustentou paradoxalmente o desenvolvimento dos mercados financeiros. A correlação estabeleceu-se com o aumento do desemprego de longa duração favorecendo a precarização dos laços empregatícios, a flexibilização no uso da mão de obra e o aumento das formas instáveis de emprego. As repercussões foram adversas de acordo com o país e sua economia. Nos países do Norte ocorreu a implantação do trabalho em tempo parcial e nos países do Sul, o crescimento do trabalho informal (HIRATA, 2002). 
$\mathrm{O}$ século $\mathrm{XX}$ se consagrou pelo modelo industrial, com a indústria mantendo grande parte do setor econômico, já o modelo pós-industrial, por sua vez, sugere uma transferência da atividade econômica da indústria para os serviços. "O processo de reestruturação produtiva do capital provocou significativas alterações em nosso capitalismo recente, de modo que ainda não temos uma visão conclusiva da configuração que vem se instalando" (ANTUNES, 2006, p.16).

No Brasil, Antunes (2006) indica que frente às mudanças implementadas pelo capital, deve-se considerar as especificidades de cada setor ou ramo produtivo para compreender a conformação produtiva, a partir das relações interfirmas e estratégias de desverticalização, como também do assalariamento, da precarização, da subcontratação e da tercerização. Assim, cada setor reage com novas formas de organização, controle e gestão da força de trabalho.

O jornalismo é visto aqui como um desses setores e a apreensão das suas transformações pode ser alcançada, também, a partir dos elementos elencados por Antunes (2006), sendo eles: mutações tecnológicas, organização do trabalho, perfil da força de trabalho e suas qualificações, mudanças na estrutura do emprego, nas formas de gestão e flexibilização do trabalho. Nesse sentido, os impactos da tecnologia associados às mudanças do mercado de trabalho no modelo pós-industrial repercutiram no campo do jornalismo em demissões, fechamento de empresas de comunicação, introdução de novas narrativas na construção do conteúdo informativo, queda de anúncios e flexibilização do trabalho e de formas de contratação.

Para os autores canadenses Charron e De Bonville (2016), já na década de 1980 as políticas de racionalização de gastos das empresas contribuíram para uma precarização do trabalho, quando "as empresas passaram a recorrer mais a jornalistas com status precário (estagiários, freelances, contratados temporários), mais sensíveis às exigências do clientepatrão" (CHARRON; DE BONVILLE, 20016, p. 369). No Brasil, nesse mesmo período também foram introduzidos os treineiros pelas empresas de comunicação, mas para Fígaro (2013) foi após a década de 1990 que se intensificou a terceirização do trabalho jornalístico com os contratos de trabalho por tempo determinado, contratos de pessoa jurídica (PJ), cooperados e freelancers.

As empresas de comunicação que antes gestavam a veiculação de impressos e que estão sobrevivendo no capitalismo pós-industrial, por sua vez, não conseguem custear a estrutura da produção da informação no modelo digital com base no modelo anterior - o industrial -, mantendo o mesmo resultado da equação custos e lucro. Antes, a indústria 
tradicional da imprensa dominava "100\% da cadeia de valor de seu negócio" (COSTA, 2014, p. 58), começava pela produção de conteúdo, passando pelo manejo técnico e distribuição. Para o autor, ela tinha total controle do negócio, contratando os produtores, comprando os sistemas de impressão e de sinal de transmissão até a realização da distribuição.

Aquele jeito antigo de produzir informação, cujo monopólio da distribuição pertencia a uma indústria chamada jornalística, mudou. Ela agora pode ser produzida e distribuída pelas mãos de qualquer um. Combinou-se meio e comunicação. Nasceu a superdistribuição (COSTA, 2014, p. 63).

Um dos seus pilares de sustentação do modelo industrial, composto pelo financiamento do anunciante e classificados, passou por novas configurações. A Internet e mídias digitais abriram outras janelas de investimento para os anunciantes, e estes não percorreram, obrigatoriamente, uma migração linear do papel para a plataforma online dentro do mesmo veículo.

A migração dos anunciantes repercutiu nos índices de circulação dos impressos. De acordo com os dados do Instituto Verificador de Comunicação (IVC), referente ao primeiro semestre de 2017, os principais jornais e revistas de tradição impressa no Brasil registraram uma queda nos índices de circulação. Ao considerar os números a partir de janeiro de 2015, a retração foi maior. Jornais que circulavam com mais de 200 mil exemplares diários passaram a vender menos de 150 mil unidades diárias (PODER $360,2017)$. Contudo, deve-se ponderar que os números das assinaturas digitais oscilam dependendo do título.

As grandes redações que predominaram no mercado editorial no auge do paradigma do jornalismo informativo, algumas como conglomerados de mídia, reduziram a um terço o número de profissionais, calçados pelo discurso da composição das redações digitais e de que o jornalista deixou de atuar apenas para uma plataforma específica (impresso, rádio ou TV), para operar no ambiente online. Na prática, o profissional que antes trabalhava para o impresso passou a produzir também para blog, Facebook, Twitter e em formatos de áudio, vídeo e texto. É o profissional denominado "perfil digital" ou "multitarefas". Novos atores sociais, como arquitetos, publicitários, designers, profissionais formados em audiovisual, computação, rádio e TV ou multimeios, ingressaram nas redações e se tornaram produtores de conteúdo informativo. 
Marcondes Filho (2009) vê esse quarto modelo do jornalismo regrado pela tecnologia e pela velocidade do sistema repercutindo diretamente no profissional e no exercício da atividade. A apropriação da informatização pelas empresas acarretou a taylorização do trabalho jornalístico, com alta rotatividade dos profissionais nas redações e o fim da especialização. Em conformidade com a proposta do autor de observar os desdobramentos diretos na atividade do profissional, esta reflexão concebe o terceiro estágio do modo de produção capitalista com uma junção do toyotismo, que entre seus atributos estão: uma intensificação da exploração do trabalho, seja pelo fato dos trabalhadores atuarem simultaneamente com diferentes máquinas, seja pelo ritmo e velocidade da cadeia produtiva; e a exigência de um trabalhador mais qualificado, multifuncional e polivalente (ANTUNES, 1999; 2018). Hoje, o perfil almejado nas redações é do profissional multimídia, ou digital, que corresponde àquele que sabe operacionalizar conteúdo para diferentes plataformas e formatos diversos (ABREU, 2017).

Bram, Weaver e Brownlee (2009) estudaram o período de 2002 a 2007, justamente quando o jornalismo americano vivenciou os efeitos da ruptura do modelo vigente que ostentou o jornalismo no século XX, com demissões por parte das organizações jornalísticas, sobrecarga de trabalho dos profissionais e desafios em produzir conteúdo com novas narrativas para as plataformas de distribuição emergentes, buscando público/ audiência. Os autores focaram nas mudanças dos indicadores de profissionalismo: autonomia, funções jornalísticas, percepção ética e adesão à organização jornalística ou de comunicação. Os resultados mostraram aspectos positivos e negativos a partir da interpretação dos papéis dos jornalistas, destacando que os jornalistas da imprensa diária perderam autonomia em comparação aos respondentes que atuavam no jornalismo online ou em revistas, devido à sobrecarga de trabalho ocasionada pelas demissões; e que os jornalistas de blogs, apesar de não terem a repercussão da mídia convencional, ajudaram a definir a agenda pública, com a produção de conteúdo.

Nesse cenário, no Brasil, segundo dados da Conta dos Passaralhos, entre 2012 a 2017, foram notificadas 2.123 demissões de jornalistas em redações e um total de 7.277 demissões em empresas de mídia. Os jornais lideraram o ranking dos cortes com jornalistas (48\%), em seguida as emissoras de rádio e televisão (27\%), revistas (14\%) e online (10\%). Ao considerar o total de demissões, as emissoras de rádio e televisão se sobressaíram com $50 \%$, em seguida os jornais $(33 \%)$, revistas $(11 \%)$ e online $(6,4 \%)$ (VOLT DATA, 2018). As fontes não incluíram assessorias de imprensa e de comunicação e a metodologia utilizada não computou as demissões individuais, o que significa que esse 
número pode ter sido ainda maior. O agravante é que em 2018 as demissões continuaram. O jornal mais antigo em circulação da América Latina, o Diário de Pernambuco, de 1825, demitiu 38 funcionários.

Outra constatação do mercado diz respeito a perdas trabalhistas e contratuais dos jornalistas (FÍGARO, 2013; MICK; TAVARES, 2017), buscando formas alheias ao regime da CLT (Consolidação das Leis de Trabalho) e incrementando o leque de opções que já existia nas décadas de 1980 e 90, como mostrou-se acima, como o contrato de prestação de serviço e o sistema de sócio participativo. A pesquisa Perfil do Jornalista Brasileiro realizada em 2012 apontou que dos jornalistas que atuavam "fora da mídia", $61 \%$ não tinha carteira de trabalho assinada; já os que trabalhavam em mídia 40,2\% eram freelancer, prestador de serviço, pessoa jurídica ou com outra forma de contratação (MICK; LIMA, 2013).

O número de empregos formais no jornalismo brasileiro há anos não supera o mercado informal e o hiato entre ambos oscila conforme os movimentos do mercado e da concorrência. Em 2002, o mercado formal representava 20\% do número total de jornalistas atuando no mercado nacional, segundo dados da RAIS (Relação Anual de Informações Sociais) (FÍGARO, 2013). Dez anos depois, ao comparar os dados da FENAJ que estimava em 145 mil jornalistas com registro profissional no país (MICK; LIMA, 2013), com os dados da RAIS de 2013, 74.487 (LEITE, 2015), constata-se que o mercado formal correspondia a $51,37 \%$ do mercado nacional.

Em paralelo ao movimento da imprensa convencional frente às transformações, há o crescimento de sites jornalísticos, com narrativas multimídias e formatos jornalísticos oportunizando reportar novos discursos e atores sociais. Levantamento da Agência Pública (2016) aponta 86 sites de jornalismo independente em funcionamento no Brasil, sendo que a maior parte deles foi criada a partir de 2010 e atende nichos específicos. Além do mapa realizado pela Pública, há um mapa paralelo abastecido pelos leitores com 139 sites. Já a pesquisa (LÜDTKE, 2016) mapeou, entre 2015 e 2016, mais de 200 iniciativas independentes. E mesmo o movimento do mercado não se resulta a uma linearidade, ou seja, a formação de novas iniciativas não é consequência apenas das demissões ou falta de opções para empregar novos profissionais da área. $\mathrm{O}$ desafio aqui é compreender as transformações no processo de trabalho do jornalismo nesse novo paradigma. 


\section{Percurso teórico-metodológico}

A metodologia envolveu uma pesquisa empírica sobre o jornal $\mathrm{O}$ Estado de $\mathrm{S}$. Paulo e o site InfoAmazônia. A coleta de dados teve como norte o referencial teórico sobre organização tecnológica do trabalho, inovação e processo de trabalho.

Mendes-Gonçalves (1992) identifica o processo de trabalho a partir de sua finalidade, seu objeto, seu conhecimento e agentes. O conceito de organização tecnológica do trabalho refere-se aos nexos estabelecidos no interior do processo de trabalho entre a atividade operante, realizada através de instrumentos, objetos de trabalho e a finalidade. O conhecimento é o principal instrumento porque orienta todo o processo. Portanto, tecnologia não tem o significado corriqueiro de conjunto de instrumentos materiais, muitas vezes associado à maior eficácia e produtividade por avanços em suas concepções operacionais (MENDES-GONÇLAVES, 1994), mas sim como se estabelece sua absorção durante o processo de trabalho e a execução da atividade.

Apreender a organização tecnológica do trabalho em jornalismo significa caracterizar os profissionais que atuam, o conhecimento que utilizam, os instrumentos que operam, os meios e as relações que estabelecem com a sociedade para atingir os fins, isto é, o produto de seu trabalho. Para a análise empírica, viu-se necessário obter informações sobre a formação dos profissionais, suas funções, processo de trabalho e as mudanças introduzidas nas empresas e no jornalismo.

A coleta dos dados ocorreu em dois movimentos de acordo com as particularidades do veículo, como estrutura da redação, processo e organização tecnológica do trabalho. No caso de O Estado de S. Paulo foram utilizadas duas técnicas, pois o jornal possui uma sede fixa com uma redação que abriga grande parte dos profissionais responsáveis pela produção de conteúdo. Em uma primeira etapa realizou-se a entrevista semiestruturada com o editor executivo de conteúdos digitais do jornal ${ }^{5}$, na qual levantaram-se informações sobre a organização do trabalho, os agentes envolvidos, o impacto da tecnologia na produção do conteúdo e o cenário de transformações do jornalismo. A segunda fase caracterizou-se pela observação na redação durante quatro dias, 24, 25, 26 e 28 de abril de 2017, com uma média de 7 horas diárias, acompanhando o processo de trabalho em reuniões de pauta, apuração, edição de conteúdo, postagem, diálogo entre repórteres, outros pares

\footnotetext{
${ }_{5}$ O projeto de pesquisa Inovação tecnológica e conhecimento científico em Jornalismo foi aprovado pelo COEP - Comissão de Ética em Pesquisas Envolvendo Seres Humanos que autorizou a realização das entrevistas com profissionais no desenvolvimento da pesquisa (62613216.1.0000.5689).
} 
e fontes. Utilizou-se também da técnica de entrevista para obter informações junto aos profissionais (jornalistas, publicitários e secretária de redação) durante a observação. A pesquisa de campo centrou-se nas editorias de rede social e home, por serem responsáveis pela centralização e publicização do conteúdo produzido nas outras editorias.

O site InfoAmazônia não possui uma sede física que abriga o processo de trabalho. Um dos idealizadores, Gustavo Faleiros, é o atual gestor da iniciativa, ele também gerencia e participa da produção de conteúdo. Como viaja muito, pois está à frente dos projetos, a entrevista dividiu-se em três etapas: um primeiro contato por telefone; depois encaminhou-se por e-mail as perguntas; e por fim, as respostas foram enviadas pelo WhatsApp, em formato de áudio, quando Gustavo estava produzindo uma reportagem no Peru. A equipe de produção é volátil, sem contrato de trabalho formal e é constituída de acordo com o projeto. Há um núcleo fixo composto por quatro profissionais: dois editores que acumulam também a função de repórter e dois programadores, sendo um responsável pela gestão do servidor e o outro mais focado nas plataformas de publicação, como mapas por exemplo (FALEIROS, 2017). Além da entrevista foi feita uma análise do site fundamentada na categoria medialidade (GRUSIN, 2010) e nos atributos da quinta geração das mídias digitais (BARBOSA, 2013).

Diferente da forma de gestão do modelo informativo, sustentado pela mídia convencional, a gestão do InfoAmazônia é caracterizada por projetos de cobertura, que precisam ser aprovados por um financiador. Nos dois primeiros anos do site, até 2014, o Client and Development Knowledge Network bancou a produção de conteúdo. Já Gustavo Faleiros conseguiu uma bolsa profissional do Centro Internacional de Jornalistas. Posteriormente, o site adquiriu outros doadores. "Os primeiros cinco anos do projeto... foram bem financiados. Agora a gente está entrando em uma fase um pouco mais difícil, uma fase de transição que a gente está pensando como sustentar o projeto" (FALEIROS, 2017).

A partir do segundo semestre de 2017, o site foi incubado por outra iniciativa de jornalismo independente brasileira especializada na região Amazônia, o site Amazônia Real ${ }^{6}$, que tem como um dos pilares de sustentação financeira a Fundação Ford. De acordo com Gustavo Faleiros (2017), a escolha pela Amazônia ocorreu devido: i) a sua expertise em jornalismo ambiental associada à disponibilidade de dados no acompanhamento do desmatamento da floresta, possibilitando o uso de jornalismo de dados, e ii) à importância do tema em âmbito nacional e internacional. Ele acrescentou ainda que durante o desenvolvimento do site e sua imersão na região, foram implantadas

${ }_{6}^{6}$ O site Amazônia Real também consta no Mapa da Pública. O site está disponível em: http://amazoniareal.com.br/ 
inovações nas temáticas de cobertura, como abordagens sobre o ambiente social com suas particularidades representadas por comunidades distintas, diversidade étnica, social, modo de produção, sustentabilidade e cultura.

\section{Resultados: Jornal O Estado de S. Paulo}

As transformações na redação do jornal ocorreram de forma processual e lenta ao longo dos anos, à medida que a empresa digeria a necessidade de mudar, devido aos impactos econômico e tecnológico. O Estadão resistiu em um primeiro momento, devido ao próprio perfil tradicional da empresa.

O editor executivo de conteúdos digitais do jornal $O$ Estado de S. Paulo, Luis Fernando Bovo descreve esse processo em fases, as quais coincidem com a literatura que estuda o jornalismo na Internet (CANAVILHAS, 2001; BARBOSA, 2013) a partir das práticas jornalísticas. A primeira fase compreendeu a simples transposição do conteúdo do papel para o digital inserindo uma chamada na home, normalmente a cargo de técnicos e não de jornalistas. A segunda fase já possuía jornalistas para produzir conteúdo para o digital, como foto, artes e pdf, além da chamada. O terceiro momento caracterizou-se pela contratação de profissionais para atuarem na produção de conteúdo online, desenhando duas redações com equipes distintas, "já começou a pensar em conteúdo específico para o digital, com galeria de foto, em vídeo e tal. Então esse foi o momento em que também era separado: tinha a equipe do papel e a equipe do digital" (BOVO, 2016). De acordo com o editor executivo, os conteúdos das duas plataformas não conversavam, "não tinha uma uniformidade no conteúdo apesar de ser ambos Estadão". A quarta fase configurou-se pela integração total das duas redações, com a absorção pelas editorias do conteúdo que antes era produzido exclusivamente pela equipe digital. "Hoje nós temos um quadro onde as editorias são responsáveis pelos seus conteúdos, seja conteúdo em redes sociais, seja conteúdo em vídeo, seja conteúdo em áudio, seja conteúdo em digital” (BOVO, 2006). A única separação é que as equipes de Home, Redes sociais e TV Estadão são puramente digitais.

Esse quarto momento iniciou-se a partir de 2010, com um processo de extinção da divisão entre redação do impresso e redação do online. Com isso aboliram editorias e suplementos, criaram as editorias de Redes sociais e TV Estadão (dentro da redação) e foram efetuadas demissões. Entre 2012 e 2016, 98 profissionais foram demitidos, além de alterarem os contratos de trabalhos dos jornalistas que atuavam na redação (VOLT 
DATA, 2018). O movimento de transposição das fases no contexto das transformações do jornalismo configurou em perdas trabalhistas, precarização e terceirização. Jornalistas que eram contratados em regime formal CLT, colunistas e profissionais com mais tempo de casa passaram a ser prestadores autônomos. Os freelancers, também com a nova política, tiveram que migrar para prestadores autônomos (CNPJ) e fecharam sucursais (restaram duas: Rio de Janeiro e Brasília). Nesse cenário, as editorias Rede Sociais, TV Estadão e a Home passaram a ocupar um espaço relevante na redação digital.

As motivações da empresa para essa nova organização do trabalho foram para garantir sua própria sobrevivência enquanto indústria, como pontua Bovo (2016):

[...]a indústria de comunicação, jornalística, está vivendo uma crise... A gente precisava sobreviver...Vamos integrar para sobreviver, não dá para um produzir para o papel ou outro para a web, não, todo mundo produz tudo. Foi uma questão de sobrevivência e hoje não é mais nem isso, já é uma questão mesmo de você atender leitor. E o leitor está aonde? Está no digital. Você tem ali um número $\mathrm{x}$ de leitores no impresso e você tem aqui um número 20 vezes $\mathrm{X}$ no digital.

O grupo hoje conta com cerca de 400 jornalistas, somando rádio, jornal, broadcasting, sucursais e agência. Há também novos atores com outra formação habitando a redação, como o publicitário que ocupa o cargo de editor de audiência e é o responsável em acompanhar o que está dando audiência e sugerir interconexões entre os conteúdos. "Ele detecta o que as pessoas estão querendo nas redes sociais e na web e faz essa ligação com o conteúdo que nós temos... ele sugere conteúdos, ele detecta antes de começar a explodir o que vai explodir, sugere, a gente produz." (BOVO, 2016). O espaço da Tecnologia da Informação (TI) abriga 15 profissionais formados em análise de sistema, engenharia de software, designer, arquiteto de informação e estatística. Na TV Estadão pessoas formadas em audiovisual são responsáveis pela produção do conteúdo. Todos esses profissionais, ao lado dos jornalistas participam diariamente do processo de trabalho de produção do conteúdo digital.

O perfil do jornalista, por sua vez, passou a ser o que as empresas denominam como "digital", isso significa ter que pensar multimídia, ou seja, incorporar a inovação tecnológica não apenas como instrumento de trabalho, mas na própria formação do profissional. A inserção de novo perfil, de acordo com Bovo (2016) foi paulatina, o próprio editor ao repor uma vaga passou a buscar esse novo profissional. A empresa também 
investe em um curso próprio para essa formação profissional, ofertado pelo seu Núcleo de Produção Multimídia. De acordo com Bovo (2016), todas as editorias têm pessoas formadas pelo Núcleo. Ele reitera que não é uma questão de geração, pois na redação há profissionais com mais tempo de casa que atuam nos blogs e ocupam o espaço digital ao lado dos profissionais mais jovens.

O "perfil digital" assemelha-se ao profissional mais qualificado, multifuncional e polivalente comumente explorado pelo terceiro estágio do capitalismo (Toyotismo). O repórter deve produzir áudio, vídeo, imagem e texto. O editor de esportes, por exemplo, é responsável pela editoria no site, na TV, na rádio e no papel. "Ele é o editor vertical de esportes... ele faz um programa de esportes na rádio, ele edita o jornal, ele faz o site, ele tem um blog e uma coluna...Ele faz tudo. Não tem mais essa coisa do profissional fazer uma coisa só", acrescenta Bovo (2016). E isso já é dito no momento da contratação, é um pacote de produtos que o profissional tem que cumprir.

Nesse cenário digital, o conhecimento não se resume à mera compreensão e instrumentalização das redes sociais, os pilares epistemológicos do jornalismo ainda prevalecem, em sintonia com a observação de Palacios (2003) de recombinar o velho e articular com o novo, na perspectiva da organização tecnológica do trabalho (MENDESGONÇALVES, 1992). Conhecer os conceitos de apuração, checagem da informação, triangulação e as deontologias do jornalismo ainda são essenciais na formação e na aplicação de procedimentos diários durante o processo produtivo. Esses elementos não são descartados no jornalismo digital. A inovação tecnológica deve ser introduzida no processo de produção para potencializá-lo e não transfigurar sua gênese. Nesse sentido, Bovo (2016) pontua a distinção entre jornalismo profissional e produção de conteúdo.

O sujeito chega na redação e acha que porque tem rede social, ele olha na rede social e vê aquilo e dá como barato, dá como novo... O cara acha que pode pegar coisa do facebook e jogar...Como é que você faz jornalismo profissional? Tem que checar fonte, resgatar essa coisa da entrevista cara a cara que hoje ninguém mais faz, hoje é tudo via e-mail (BOVO, 2016).

A inovação tecnológica é absorvida pelo processo de trabalho na produção do conteúdo. A cobertura digital é discutida no planejamento da pauta, durante a reunião quando é analisada a forma adequada para expor o conteúdo, seja em um gráfico, em uma galeria de fotos, em um vídeo reportagem, em 300 tweeds, ou vídeo de um minuto, ou áudio, ou podcast, ou texto, ou mesmo uma conjunção de formatos. Ali já é decidido 
como a história será contada para melhor compreensão do público. É nesse momento do planejamento, que segundo Bovo (2016), entra todo o aparato tecnológico para pensar o processo.

A editoria por exemplo de política vai planejar a cobertura de eleição. Ela vai falar olha isso aqui eu vou fazer em galeria, isso aqui eu vou fazer em ao vivo, isso aqui eu vou fazer em vídeo, isso aqui eu vou fazer em periscope $^{7}$, isso aqui eu vou fazer uma reportagem grande com uma galeria de fotos e isso aqui eu vou botar no papel. Então esse planejamento e essa produção são feitos pela editoria.

Outra alteração na organização do trabalho é a antecipação da produção de conteúdo, enquanto antes no modelo industrial a velocidade de produção era regida por um fechamento diário, no digital há vários fechamentos ao longo de um dia de rotina produtiva. A audiência também tem um perfil mais diversificado, o que repercute no planejamento diário de conteúdo e no próprio fechamento.

Outro indicador que direciona o planejamento dos fechamentos no decorrer do dia é a análise dos picos de audiência, horários e preferências da audiência, determinando a inserção de novos conteúdos, alterações na disposição e visualização na home e o tipo de conteúdo a ser publicizado. Durante a observação constatou-se essa alternância da disposição do conteúdo na página, conforme os profissionais da home constatavam o acesso e a visualização pelo público. Essa é uma atividade incorporada na rotina produtiva diária pelos e pelas profissionais da editora de home.

O fechamento contínuo estabeleceu a organização das jornadas de trabalho, como propósito de garantir a produção e postagens sobretudo nos horários de audiência. As jornadas são intercaladas, mas acabam ultrapassando as setes horas de trabalho (cinco horas diárias mais duas horas contratuais). De acordo com Bovo (2016), a média é entre 8 a 10 horas. E há profissionais trabalhando durante a madrugada e escalas de plantão nos finais de semana e feriados.

Tudo que é postado e mesmo o movimento de alternância da posição do conteúdo na home é discutido com o diretor executivo. Durante o período de observação ocorreu a greve geral, em 28 de abril de 2017. Nesse dia, excepcionalmente, toda a rotina da redação foi alterada e constatou-se uma maior autonomia por parte dos e das profissionais nas editorias de rede social e home em relação à postagem dos conteúdos, ocasionada pelo grande fluxo de informação que chegava à redação e pela necessidade de publicá-los rapidamente.

$\overline{7}$ É um aplicativo que permite fazer vídeo e divulgar em tempo real. 


\section{InfoAmazônia}

O InfoAmazônia é resultado da ideia de criação de um site de jornalismo de dados associada ao uso de imagens de satélites, para ilustrar as reportagens e também para informar as investigações das reportagens. Em 2008, Gustavo Faleiros teve contato com a tecnologia do Google Earth para narrar histórias geolocalizadas via mapas interativos e, nessa mesma época, estabeleceu parceria com Earth Journalism Network. Somente em 2012 a ideia de fato se concretizou, pois, até então, não encontraram fundos para bancar o projeto. Equacionar formas de financiamento e modelos de gestão ainda é um desafio para as novas iniciativas digitais no novo paradigma do jornalismo.

O escopo sobre Amazônia envolvia tanto o acesso a dados públicos sobre o desmatamento na região, quanto a importância do tema na prática do jornalismo ambiental, a princípio surgiu com um perfil segmentado em Meio Ambiente. Apesar da jovialidade do site, ao longo desses anos, a linha editorial estabeleceu novos recortes, conforme a equipe foi conhecendo a região e a diversidade humana e cultural que abriga:

[...] ao longo dos anos outras coisas foram surgindo que reforçaram essa percepção de que é uma região importante, que tem histórias para serem contadas... Hoje em particular eu estou muito focado nesta questão de olhar outros aspectos que sejam sócio ambientais...

[...] a gente de $\mathrm{O}$ Eco começou muito focado na questão ambiental mas hoje eu já estou bem mais interessado no aspecto sócio ambiental tanto das questões indígenas mas também da cultura, questões relacionadas a saúde, alimentação na Amazônia são essenciais para a gente fazer uma cobertura bem feita (FALEIROS, 2017)

O financiamento do site também está inserido em uma lógica diferenciada da empregada no modelo industrial. Entre a concepção da ideia e sua materialização transcorreram quatro anos em busca de fundos para bancar o projeto. Somente no final de 2011, o fundo Client and Development Knowledge Network aprovou a proposta e passou a financiar parte do projeto. "A gente conseguiu outros doadores que complementaram o projeto e então os primeiros cinco anos do projeto...foram bem financiados". Ainda não há uma estabilidade financeira, por ser uma iniciativa independente e sem anunciantes. Periodicamente a equipe precisa buscar novos fundos para bancar a produção do conteúdo, como doadores, fundações ou entidades não lucrativas. 
A questão financeira está correlacionada à proposta de exercer um jornalismo independente, o que acaba repercutindo na organização tecnológica do trabalho do site e na própria morfologia da redação com relação aos cargos e funções. Segundo Faleiros (2016) no momento da entrevista eram quatro pessoas trabalhando. Outra peculiaridade é a volatilidade de envolvidos na produção de conteúdo de acordo com o projeto da pauta e sua aprovação. "Então teve momentos que a gente tinha 14 pessoas trabalhando em vários projetos e no ano passado fomos de novo, sei lá, quase 10 pessoas trabalhando em novos projetos e agora, nesse momento de transição, a gente tem que buscar novos projetos" (FALEIROS, 2017). Além de não ter uma equipe fixa, nenhum deles dedica-se integralmente ao site, justamente pela falta de suporte financeiro.

O processo de trabalho para a produção de conteúdo também muda de acordo com o planejamento da pauta, mas o curioso é que envolve equipe multidisciplinar com formação diversa, executando expertises da narrativa digital (web jornalismo) e de jornalismo de dados. Um exemplo apontado é o Alerta de enchentes (INFOAMAZÔNIA, 2017) que obteve recursos para realizar 25 reportagens, com viagens a campo e produção de vídeos. Há produções complexas como a cobertura A Política do desmatamento (FALEIROS et al, s/d), que embora fosse constituída por uma equipe menor, entre 6 a 8 pessoas, incluindo pessoal de vídeo e análise de dados, um consultor para checar os dados, dois programadores - um para fazer mais análise de dados estrutural, banco de dados e outro para fazer toda a parte de front-end ${ }^{8}$-, um redator chefe, um editor, também recorreu a especialistas.

[...] então é um projeto que teve uma equipe multidisciplinar... esse projeto eu menciono porque ele é o principal exemplo de como é estruturada a produção diferente de uma reportagem tradicional, mesmo especial. A gente juntou uma equipe muito grande. Trabalhou por seis meses levantando dados, baixando dados, depois estruturando nossos próprios bancos de dados, com uma equipe de vídeos que montou vídeos que iam na plataforma, então esse é um trabalho bem mais amplo, assim nesse aspecto. Tem tanto o tradicional de produção de conteúdo dentro de um projeto quanto a gestão de equipes multidisciplinares, que é o aspecto mais diferente. Como o caso do Alerta de enchentes que a gente trabalhou também com uma equipe de desenvolvedores da Universidade Federal de Campina Grande que fez toda a parte de estruturação de banco de dados e criou um aplicativo que funciona no Messenger do Facebook. (FALEIROS, 2017).

8 "O front-end é uma abstração, simplificando o componente subjacente pelo fornecimento de uma interface amigável, como por um exemplo um navegador de Internet, ou um formulário para um determinado usuário” (WIKIPÉDIA, s/d). Disponível em: https://pt.wikipedia.org/wiki/Front-end_e_back-end 
De maneira geral, os projetos recrutam desenvolvedores de manutenção dos servidores, de visualização de dados, de confecção de mapas interativos, de hardwares. Grande parte dos profissionais são formados em ciência da computação. Também envolvem especialistas em análise de dados, videomaker e jornalistas. Quando necessário recorrem a profissionais específicos, como antropólogos para ajudar na interpretação dos dados. A jornada de trabalho é volátil. Eles são contratados por projetos, sem CLT.

O site não segue uma periodicidade na publicação dos conteúdos. A lógica de produção das reportagens é determinada pela pauta, suas particularidades e recursos financeiros. Porém, deve-se considerar que há uma lógica, contudo não corresponde à lógica do modelo industrial e das redações dos veículos tradicionais. A rotina da produção de conteúdo jornalístico durante o processo de trabalho oscila de acordo com o projeto e as funções desempenhadas, pois, a demarcação é tênue. Dependendo da história, o processo de produção pode demorar uma semana. Já a produção do projeto de cobertura da política do desmatamento durou seis meses.

A produção diária corresponde a três frentes: notas mais curtas, que seguem a mesma lógica produtiva do processo da redação tradicional do modelo industrial - apuração por telefone e publicação; o trabalho de curadoria de conteúdo, republicando conteúdos de parceiros do InfoAmazônia; e, ainda, a distribuição de conteúdo pelo Facebook.

A redação online configurou-se com uma estrutura mais enxuta e "virtual". As relações de trabalho são flexibilizadas e tercerizadas e o processo de trabalho apontou acúmulo de funções desempenhadas pelo mesmo profissional, compartilhando as constatações de Mick e Lima (2013), Fígaro (2013) e Leite (2015). Já a organização tecnológica do trabalho configurou-se na absorção da inovação no processo de instrumentalização tanto nos procedimentos de apuração, quanto no de construção da narrativa, explorando a multimidialidade e a expertise de profissionais de áreas diferentes. As rotinas não são guiadas por um horário de fechamento diário ou pré-determinado, tudo depende das exigências e do planejamento da pauta. O profissional também apresenta uma formação diversificada e qualificada. Gustavo Faleiros especializou-se em jornalismo ambiental, análise de base de dados e gestão.

De acordo com Faleiros (2017), a formação atual para atuar no mercado diversificado do jornalismo, no século XXI, demanda um conhecimento em empreendedorismo e gestão em jornalismo. 
A questão do empreendedorismo é um pouco nessa linha de buscar isso que a gente está chamando de inovação, talvez seja uma palavra um pouco controvertida, mas há essa abertura para pessoas que tem mais disponibilidade, disposição a empreender, a criar coisas novas, a criar um projeto novo. Mesmo de novo que seja dentro de uma redação, ou de uma empresa que não seja a sua. (FALEIROS, 2017).

A análise do site apontou que o InfoAmazônia trabalha com mapas interativos, bases de dados abertas para o público, vídeos, imagens e infográficos, enquadrando-se na quinta geração, de acordo com a conceituação de Barbosa (2013). O conteúdo está disponibilizado em cinco seções (Notícias, Projetos, Mapas, Dados e Blog) com links para outras páginas transversais à temática abordada.

As seções Mapas e Dados do InfoAmazônia apresentam conteúdo a partir de bases de dados. Barbosa, Normande e Almeida (2014, p. 6) apontam as bases de dados como estrutura fundamental na representação de informações, "seja por meio de metadados, data mining, tagging, squarified, entre outros". A seção Projetos é composta por mapas, dados abertos e interatividade. O projeto Alerta de enchentes, por exemplo, trata-se de uma "plataforma piloto para informar com antecedência as comunidades locais sobre os riscos de enchentes" e também "jornalistas e pesquisadores para análises históricas de níveis dos rios" (INFOAMAZÔNIA, 2017). O projeto Cartografia de Ataques contra Indígenas (SANTINI, 2017) traz um mapa interativo, com georreferenciamento de informações e disponibilidade de dados, apresentando registros de assassinatos de indígenas em todo o território nacional, indicando quantidade, constância e período.

A observação da seção Notícias sugeriu conteúdos com escopo na região Amazônica e reconhecimento da diversidade regional, sobretudo do ambiente social: reportam sobre indígenas, população ribeirinha e seringueiros, por exemplo. Identificou-se pauta com perspectiva de outro modo de vida, com empoderamento de fontes populares e não consolidado em fontes oficiais. Como também se deparou com pautas de conteúdo sobre desmatamento, presentes na mídia convencional ${ }^{9}$.

\footnotetext{
9 Rocha, Santos, Colussi (2018) analisaram textos jornalísticos postados na seção Notícias do site InfoAmazônia para aferir se há perspectiva de inclusão de pautas e posicionamentos contra-hegemônica na proposta jornalística. E constataram uma pluralidade e empoderamento das fontes populares na construção do texto e seleção de pauta.
} 


\section{Considerações finais}

Apesar das duas análises corresponderem a configurações distintas no que diz respeito à linha editorial, desenho da redação digital, rotinas de fechamento, público, modelo de gestão, posição geográfica, financiamentos e longevidade, o estudo apontou similaridades. Ambos estão vivenciando as transformações do jornalismo no contexto pós-industrial e testando a inovação tecnológica nas práticas jornalísticas.

$\mathrm{Na}$ organização tecnológica do trabalho ambos incorporaram a inovação tecnológica no processo de produção do conteúdo, incrementando a expertise de novos atores na participação do processo de trabalho. Entretanto, a redação convencional mantém a lógica de produção com periodicidade diária, com o agravante de ao derrubar as paredes das editorias, ela colocou os jornalistas produzindo para multiplataformas digitais (texto, áudio, audiovisual) e desempenhando multirarefas ('perfil do jornalista digital"). As jornadas de trabalho permaneceram extensas (8 a 10 horas), com menos profissionais produzindo para o ambiente digital.

O discurso de que a tecnologia foi um facilitador na configuração de uma redação digital, soa distorcido ao observar a organização, o processo de trabalho e os cortes de funções e cargos. Há mais cobranças de produtividade e acúmulo de funções, exigidos por um modelo de gestão ainda ancorado na mesma equação do jornalismo industrial.

A redação nativa no ambiente digital, por sua vez, não segue a lógica da produção periódica. Há periodicidade apenas na postagem de notas no site, curadoria e postagens nas redes sociais. Porém, há uma lógica que orienta a produção dos projetos e reportagens, a qual é sustentada pelo custo de produção, recursos financeiros, profissionais envolvidos e características da pauta. Conotou-se uma maior exploração da inovação tecnológica na produção de conteúdo e maior autonomia para propor pautas. Contudo, deve-se ressaltar que o site ainda não usufrui de um modelo de sustentação consolidado, com precarização e flexibilização da mão de obra profissional.

No contexto das transformações do jornalismo, o conhecimento relacionado às práticas sociais está presente na organização do trabalho de produção do conteúdo jornalístico, assim como a preocupação com as deontologias do jornalismo e conceitos que nortearam os paradigmas anteriores. O que se percebeu foi a absorção da inovação tecnológica nas etapas de construção do conteúdo, direcionando movimentos particulares a cada um na lógica de produção. 
A organização tecnológica do trabalho incorporou de forma ativa um novo ator no planejamento das ações, o público/audiência, tanto na preocupação em considerar a multimidialidade na constituição da narrativa quanto na sua propagação. Essa incorporação também se associa à inclusão dos novos atores e suas expertises. Os determinantes econômicos e sociais atuaram como agentes das transformações do jornalismo, no tensionamento e na necessidade de conceber novos modelos de gestão e formas de financiamento.

Dialeticamente à busca de sobreviver e existir enquanto empresa jornalística no terceiro estágio do modo de produção do capitalismo, está o compromisso em fazer jornalismo, alicerçado aos pilares de sua gênese, compreendido aqui nas pautas de coberturas jornalística e sua relevância social, polifonia de fontes e balizas editorias gestadas em respeito aos direitos de todos os cidadãos, em denunciar desigualdades sociais, corrupção, crimes e demandas de políticas públicas. O processo de trabalho fragmentado e estrangulado pelo excesso de funções, precarização e flexibilização da mão de obra, independente dos horários de fechamento, sinalizou abalar a autonomia dos profissionais durante a produção de conteúdo. Parece que as organizações tecnológicas do trabalho institucionalizadas pelas empresas ainda não conseguiram atender essa aresta, mas acredita-se que é necessário um estudo mais profundo para analisar esta percepção.

Assim, apontamos que esta pesquisa não traz respostas definitivas, inclusive por considerar que as transformações são processuais e que o quarto modelo paradigmático do jornalismo ainda está em construção. Ressalta-se aqui que o site InfoAmazônia apresentou maior autonomia em relação ao desenvolvimento das pautas e com menos amarras nos poderes vigentes, sobretudo locais: econômico e político. Identificaram-se coberturas de interesse público e relevância social.

\section{Referências}

ABREU, A. A. de. Desafios da notícia. O jornalismo brasileiro ontem e hoje. Rio de Janeiro: FGV Editora, 2017.

AGÊNCIA PÚBLICA. Mapa do Jornalismo Independente, 2016. Disponível em: http:// apublica.org/mapa-do-jornalismo/. Acesso em: 20 maio 2016. 
ANTUNES, R. (org.). Riqueza e miséria do trabalho no Brasil. São Paulo: Boitempo, 2006.

ANTUNES, R. (org.)._Os sentidos do trabalho: ensaio sobre a afirmação e a negação do trabalho. São Paulo: Boitempo, 1999.

ANTUNES, R. (org.). O privilégio da servidão. O novo proletariado de serviços na era digital. São Paulo: Boitempo, 2018.

BARBOSA, S. Jornalismo convergente e continuum multimídia na quinta geração do jornalismo nas redes digitais. In: CANAVILHAS, J. (Ed.), Notícias e Mobilidade. O Jornalismo na Era dos Dispositivos Móveis, Covilhã, PT: Livros LabCOM, 2013. p. 33-54.

BOVO, L.F. Entrevista com o editor executivo Luís Fernando Bovo, realizada na redação do jornal O Estado de S. Paulo, aprovada pelo Comitê de Ética em Pesquisa com Seres Humanos, número CAAE 62613216.1.0000.5689. Plataforma Brasil, 28 de novembro de 2016.

BRAM, B.J.; WEAVER, D.H.; BROWNLEE, B.J. Changes in professionalism of U.S. journalists in the turbulent twenty-first century,London:Taylor e Francis, 2009.

CANAVILHAS, J. M. Webjornalismo Considerações gerais sobre jornalismo na web, 2001. Disponível em: http//www.bocc.ubi.pt/pag/canavilhas-joao-webjornal.pdf. Acesso em:18 nov. 2018.

CHARRON, J.; DE BONVILLE, J. Natureza e transformação do jornalismo. Florianópolis: Ed. Insular, 2016.

COSTA, C.T. Um modelo de negócios para o jornalismo digital. Revista de Jornalismo ESPM, n. 9, p.51-115, Abril/Maio/Junho 2014.

FALEIROS, G. Entrevista com o idealizador do site Gustavo Faleiros, realizada por WhatsApp, aprovada pelo Comitê de Ética em Pesquisa com Seres Humanos, número CAAE 62613216.1.0000.5689. Plataforma Brasil, 13 de maio, 2017.

FALEIROS, G. et al. A Política do desmatamento. Disponível em: https://desmatamento. infoamazonia.org/. Acesso em: 18 nov. 2017.

FÍGARO, R. As mudanças no mundo do trabalho do jornalista. São Paulo: Atlas, 2013.

FREIDSON, E. Renascimento do profissionalismo. São Paulo, Edusp, 1998. 
GRUSIN, R. Premediation: affect and mediality after 9/11. London, New York: Palgrave, 2010.

HIRATA, H.Nova divisão sexual do trabalho?: um olhar voltado para a empresa e a sociedade. São Paulo: Boitempo, 2002.

INFOAMAZÔNIA. Alerta de enchentes, 2017. Disponível em: https://infoamazonia.org/pt/ projects/. Acesso em: 18 nov. 2017

LEITE, A. T. B. Profissionais da mídia em São Paulo: Um estudo sobre profissionalismo, diferença e gênero no jornalismo. São Carlos: UFSCar, 232p. Tese (Doutorado) - Programa de Pós-Graduação em Ciências Sociais, Faculdade de Ciências Sociais da Universidade Federal de São Carlos, São Carlos, 2015.

LOBATO, E. Projeto de lei prevê fim do monopólio, 5 de dezembro de 1996. Disponível em: https//www1.folha.uol.com.br/fsp/1996/12/05/dinheiro/12.html. Acesso em: 11 mar. 2018.

LÜDTKE, S. Empreendimentos Digitais no Jornalismo Brasileiro, 2016. Disponível em: http://interatores.com.br/como-estao-sendo-planejadas-as-iniciativas-em-jornalismo-digitalno-brasil/. Acesso em: 5 jun. 2018.

MARCONDES FILHO, C. Ser jornalista: o desafio das tecnologias e o fim das ilusões. São Paulo: Paulus, 2009.

MENDES-GONÇALVES, R. B. O processo de trabalho e necessidades. São Paulo, Prefeitura Municipal de São Paulo (Caderno CEFOR), 1992.

MENDES-GONÇALVES, R. B. Tecnologia e organização social das práticas de saúde: características tecnológicas do processo de trabalho na rede estadual de Centros de Saúde de São Paulo, São Paulo: Hucitec/Abrasco, 1994.

MICK, J.; LIMA, S. Perfil do jornalista brasileiro. Características demográficas, políticas e do trabalho. Florianópolis: Insular, 2013.

MICK, J.; TAVARES, L. M. A governança do jornalismo e alternativas para a crise. Brazilian Journalism Research, v.13, n.2,p. 122-145, 2017.

PALACIOS, M. Ruptura continuidade e potencialização no jornalismo online: o lugar da memória. In: MACHADO, E.; PALACIOS, M. (org.). Modelos de jornalismo digital. Salvador: Calandra, 2003. 
PODER 360. Jornais e revistas: circulação impressa e digital tem queda no $1^{\circ}$ semestre, 5 de ago de 2017. Disponível em https://www.poder360.com.br/midia/jornais-e-revistas-circulacaoimpressa-e-digital-tem-queda-no-1-semestre/. Acesso em: 23 jan. 2018.

RIBAS, Gustavo Panacioni. (In)Dependência das iniciativas jornalísticas digitais do século XXI com escopo na região Amazônica: Análise dos sites Amazônia Real e InfoAmazônia. Dissertação de mestrado defendida no Programa de Pós-Graduação em Jornalismo da Universidade Estadual de Ponta Grossa, 2017.

RIFKIN, J. The end of work. The decline of the global labor force and the dawn of the post-market era, New York: Tarcher Putnam Book, 1995.

ROCHA, P. M.; SANTOS, A.S.; COLUSSI, J. Periodismo digital e inclusión de diversas comunidades de la región amazónica: estudio de la web InfoAmazônia In: XIV Congreso de la Asociación Latinoamericana de Investigadores de La comunicación, 14, realizado de 30 de julho a 1 de agosto de 2018, na Universidade da Costa Rica. Anais [...]. Costa Rica: ALAIC, 2018. v.14. p. $20-25$

SANTINI, D. Cartografia de Ataques contra Indígenas, 2017. Disponível em: https:// infoamazonia.org/pt/projects/portugues-caci-cartografia-de-ataques-contra-indigenas/. Acesso em: 18 nov. 2017

SEMBRAMEDIA. Ponto de Inflexão. Impacto, ameaças e sustentabilidade. 2017. Disponível em: http//data.sembramedia.org/?lang=pt-br. Acesso em:19 nov. 2018.

VOLT DATA. A conta dos Passaralhos, 2018. Disponível em http://passaralhos.voltdata.info/ graficos.html. Acesso em: 5 jan. 2018.

${ }^{1}$ Professora do Programa de Pós-Graduação em Jornalismo da Universidade Estadual de Ponta Grossa. Professora do curso de Jornalismo da mesma instituição. Pesquisadora colaboradora do LabJor (UNICAMP; 2008-2019). Graduada em Jornalismo e Ciências Sociais. Mestre e doutora em Sociologia pela UFSCAR. Pós-doutora em Jornalismo pela Universidade Fernando Pessoa (PT). Bolsista produtividade em Pesquisa e Desenvolvimento Tecnológico - Fundação Araucária (Convênio 049/2019). E-mail: paulamelani@gmail.com. 
${ }^{2}$ Graduada em Comunicação Social, especialidade Jornalismo, pela Pontifícia Universidade Católica de Campinas, mestre e doutora em Política Científica e Tecnológica, pela Universidade Estadual de Campinas e Especialização em Jornalismo Científico, pelo Labjor/IG/IA/Unicamp. Pesquisadora do Laboratório de Estudos Avançados em Jornalismo da Unicamp. Coordenadora do Programa de web rádio e podcast Oxigênio. Coordenadora do Núcleo de Desenvolvimento da Criatividade (Nudecri). E-mail: sim.fig@gmail.com. 